\title{
Harmonic Response Analysis of a Kind of Adjustable Hybrid Oil Film Bearing in High-speed Roll Grinder
}

\author{
Huaichao $\mathrm{Wu}^{\mathrm{a}}$, Xiangjie Meng ${ }^{\mathrm{b}}$, Zhe $\mathrm{Li}^{\mathrm{c}}$, Lv Yang ${ }^{\mathrm{d}}$ and Fang Huang ${ }^{\mathrm{e}}$ \\ School of Mechanical Engineering, Guizhou University, Guiyang 550025, China \\ aemail: magoubs@sina.com, bemail: mengxiangjie0830@163.com, 'email: lizhe199261@sina.com, \\ demail: green_yang@126.com, eemail: cme.fhuang@gzu.edu.cn
}

Keywords: Roll Grinder; High-speed Grinding; Hybrid Oil Film Bearing; Harmonic Response Analysis

\begin{abstract}
Hybrid oil film bearing in the grinding head will be subjected to various periodic persistent excitation in the course of working of high-speed roll grinder, and this will affect seriously life of the bearing and even performance of the whole roll grinder. In order to reveal sustained dynamic response characteristics of a kind of adjustable hybrid oil film bearing in high-speed roll grinder, finite element harmonic response analysis of the bearing in different adjusting positions are performed on the basis of analyzing its structure and working principle, thus, dangerous vibration frequency of the bearing is found out, and safe excitation frequency range is confirmed. These results will provide parameter basis for further revealing dynamic properties of the bearing, and also provide theory guide for its practical application.
\end{abstract}

\section{Introduction}

High speed and high precision is one of the development trends of machine tool, and with the enhance of speed and precision of machine tool, higher design and manufacturing requirements are put forward for dynamic properties of some key components ${ }^{[1]}$. Oil film bearing is considered as an important component of high-speed roll grinder, and its dynamic properties are a key of affecting performances of the whole roll grinder.

At present, bearings applied in roll grinder are often hybrid oil film bearing, because it synthesizes the characteristics of hydrodynamic oil film bearing and hydrostatic oil film bearing, and it has the following prominent advantages: small wear, large load capacity, long life, wide speed range, good dynamic property and high rigidity ${ }^{[2-4]}$. With the enhance of speed of roll grinder, vibration of hybrid oil film bearing in the grinding head brought by high speed will reduce processing quality ${ }^{[5]}$. Therefore, in order to reveal dynamic properties of hybrid oil film bearing in high-speed roll grinder, the first problem to be solved is reveal its natural frequency and find out its vibration vulnerable areas in high-speed working condition; furthermore, hybrid oil film bearing will be subjected to various periodic persistent excitation in the course of high-speed working, and range of loading variation is also very wide, thus, service life of the bearing will be shorten greatly. So, harmonic response performances need to be also analyzed for revealing dynamic properties of the bearing, the goal is to acquire the response of displacement of the bearing to frequency, thus, the sustained dynamic response characteristics of the bearing can be confirmed.

\section{Structure of the Adjustable Hybrid Oil Film Bearing in High-speed Roll Grinder}

Assembly drawing of the adjustable hybrid oil film bearing in high-speed roll grinder is shown in Fig.1, and its unfolded drawing is shown in Fig. $2^{[6]}$. It can be seen from Fig.1 and Fig.2 that the bearing is mainly composed of bearing body, bearing sleeve and regulating mechanism, and the regulating mechanism is mainly composed of front and back adjusting push plates, front and back adjusting covers. In the assembly process of the bearing body with bearing sleeve, sunken deformation will occur on the bearing body, and eight wedge-type dynamic pressure oil cavities are forced to form under the action of squeezing ${ }^{[6]}$. In addition, four static pressure oil cavities are designed for the bearing, which are distributed uniformly on inner surface of the bearing body, 
and their is an oil guide slot in the middle of every two static pressure oil cavities. In the course of starting and stopping, oil film static pressure which comes from four static pressure oil cavities can make the spindle suspend in the middle of inner surface of the bearing, thus, dry friction can be avoided. In the course of running, oil film dynamic pressure formed in eight wedge-type dynamic pressure oil cavities and oil film static pressure come from four static pressure oil cavities sustain together the spindle running in high speed state, and oil film dynamic pressure play the leading role.

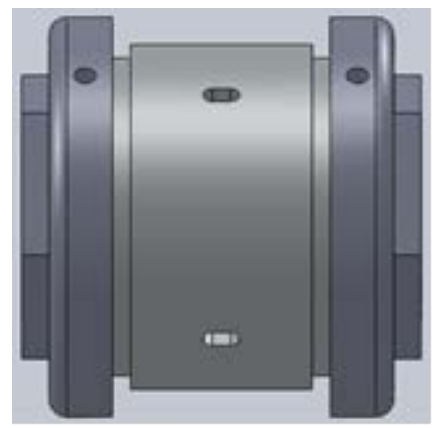

Fig.1 Assembly drawing of the hybrid oil film bearing

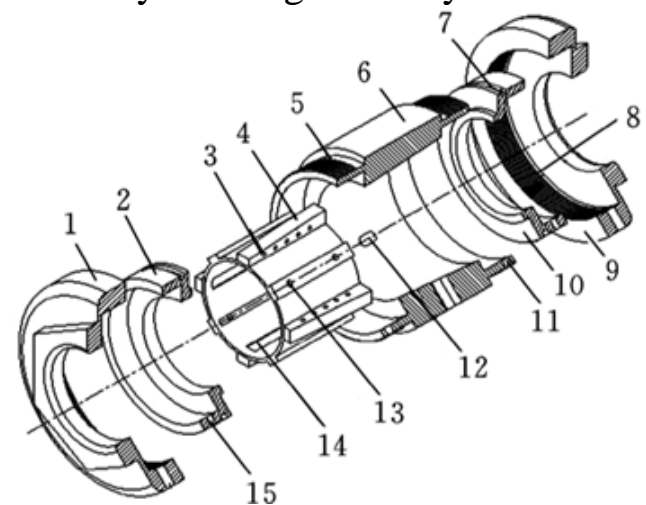

1. Front adjusting cover; 2. Front adjusting push plate; 3. Oil guide hole on bearing body; 4. Bearing body; 5. External thread on bearing sleeve; 6. Bearing sleeve; 7. Seal ring; 8. Internal thread on back adjusting cover; 9. Back adjusting cover; 10. Back adjusting push plate; 11. Oil return hole on bearing sleeve; 12 . Oil entrance hole on bearing sleeve; 13 . Oil entrance hole on bearing body; 14 . Static pressure oil cavity; 15. Oil return hole on front adjusting push plate

Fig.2 Unfolded drawing of the hybrid oil film bearing

In order to meet the demand of roll grinding in different loading condition, the bearing shown in Fig.2 can be adjusted ${ }^{[6]}$. When the front and back adjusting covers are screwed to left simultaneously (view direction shown in Fig.2), the back adjusting push plate is forced to move to left, and then the bearing body and the front adjusting push plate is pushed to left, thus, tapered match degree between the bearing body and the bearing sleeve is increased, and sunken deformation degree of the bearing body is also increased, accordingly, shapes of eight dynamic pressure oil cavities are changed, and their areas are increased. When sunken deformation degree of the bearing body needs to be decreased, that is to say, areas of eight dynamic pressure oil cavities need to be decreased, the front and back adjusting cover need to be screwed to right simultaneously.

\section{Harmonic response analysis of the bearing in different adjusting positions}

Aiming at the adjustable hybrid oil film bearing in high-speed roll grinder shown in Fig.1 and Fig.2, ANSYS software will be used to analyze its harmonic response performances. Because the bearing shown in Fig. 1 and Fig. 2 is a kind of adjustable bearing, three representative positions are selected to analyze their harmonic response performances, and the three positions are as follows: the middle adjusting position, the extreme left adjusting position and the extreme right adjusting position, that is, the bearing body is located in middle, extreme right, or extreme right of adjusting range. According to finite element analysis method ${ }^{[7]}$, harmonic response analysis grid model is built firstly, and then harmonic excitation whose frequency range is $0 \mathrm{~Hz}-3150 \mathrm{~Hz}$ is applied in the 
inner surface of the bearing grid model. When the inner surface of the bearing is set as stress surface, and two end surfaces of the bearing are set as fixed surfaces, displacement response values in $\mathrm{x}$ direction(axial direction), y direction(horizontal radial direction) and $\mathrm{z}$ direction(vertical radial direction) of the inner surface of the bearing body are acquired by calculating, and Table 1- Table 3 show respectively the displacement response values of three adjusting positions under differet frequencies.

Table 1 Displacement response values of the bearing in the middle adjusting position

\begin{tabular}{cccc}
\hline Frequency $(\mathrm{Hz})$ & $\begin{array}{c}\text { Displacement in } \\
\text { x direction }(\mathrm{mm})\end{array}$ & $\begin{array}{c}\text { Displacement in } \\
\text { y direction }(\mathrm{mm})\end{array}$ & $\begin{array}{c}\text { Displacement in z } \\
\text { direction }(\mathrm{mm})\end{array}$ \\
\hline 450 & $1.47 \mathrm{E}-05$ & $6.80 \mathrm{E}-03$ & $1.35 \mathrm{E}-03$ \\
900 & $1.61 \mathrm{E}-05$ & $7.19 \mathrm{E}-03$ & $1.38 \mathrm{E}-03$ \\
1350 & $1.89 \mathrm{E}-05$ & $7.97 \mathrm{E}-03$ & $1.43 \mathrm{E}-03$ \\
1800 & $2.44 \mathrm{E}-05$ & $9.56 \mathrm{E}-03$ & $1.48 \mathrm{E}-03$ \\
2250 & $3.63 \mathrm{E}-05$ & $1.35 \mathrm{E}-02$ & $1.77 \mathrm{E}-03$ \\
2700 & $5.64 \mathrm{E}-05$ & $6.35 \mathrm{E}-02$ & $1.62 \mathrm{E}-02$ \\
3150 & $1.88 \mathrm{E}-04$ & $3.74 \mathrm{E}-04$ & $5.01 \mathrm{E}-05$ \\
\hline
\end{tabular}

Table 2 Displacement response values of the bearing in the extreme left adjusting position

\begin{tabular}{cccc}
\hline Frequency $(\mathrm{Hz})$ & $\begin{array}{c}\text { Displacement in } \\
\text { x direction }(\mathrm{mm})\end{array}$ & $\begin{array}{c}\text { Displacement in } \\
\text { y direction }(\mathrm{mm})\end{array}$ & $\begin{array}{c}\text { Displacement in } \\
\mathrm{z} \text { direction }(\mathrm{mm})\end{array}$ \\
\hline 450 & $5.85 \mathrm{E}-05$ & $6.64 \mathrm{E}-03$ & $1.39 \mathrm{E}-03$ \\
900 & $6.16 \mathrm{E}-05$ & $7.00 \mathrm{E}-03$ & $1.42 \mathrm{E}-03$ \\
1350 & $6.78 \mathrm{E}-05$ & $7.74 \mathrm{E}-03$ & $1.47 \mathrm{E}-03$ \\
1800 & $8.06 \mathrm{E}-05$ & $9.22 \mathrm{E}-03$ & $1.54 \mathrm{E}-03$ \\
2250 & $1.12 \mathrm{E}-04$ & $1.27 \mathrm{E}-02$ & $1.90 \mathrm{E}-03$ \\
2700 & $4.92 \mathrm{E}-04$ & $4.96 \mathrm{E}-02$ & $1.19 \mathrm{E}-02$ \\
3150 & $6.98 \mathrm{E}-05$ & $7.59 \mathrm{E}-04$ & $1.10 \mathrm{E}-03$ \\
\hline
\end{tabular}

Table 3 Displacement response values of the bearing in the extreme right adjusting position

\begin{tabular}{cccc}
\hline $\begin{array}{c}\text { Frequency } \\
(\mathrm{Hz})\end{array}$ & $\begin{array}{c}\text { Displacement in } \\
\mathrm{x} \text { direction }(\mathrm{mm})\end{array}$ & $\begin{array}{c}\text { Displacement in y } \\
\text { direction }(\mathrm{mm})\end{array}$ & $\begin{array}{c}\text { Displacement in } \\
\mathrm{z} \text { direction }(\mathrm{mm})\end{array}$ \\
\hline 450 & $1.42 \mathrm{E}-05$ & $6.76 \mathrm{E}-03$ & $1.37 \mathrm{E}-03$ \\
900 & $1.42 \mathrm{E}-05$ & $7.13 \mathrm{E}-03$ & $1.40 \mathrm{E}-03$ \\
1350 & $1.37 \mathrm{E}-05$ & $7.90 \mathrm{E}-03$ & $1.44 \mathrm{E}-03$ \\
1800 & $1.09 \mathrm{E}-05$ & $9.43 \mathrm{E}-03$ & $1.49 \mathrm{E}-03$ \\
2250 & $5.12 \mathrm{E}-06$ & $1.31 \mathrm{E}-02$ & $1.90 \mathrm{E}-03$ \\
2700 & $4.36 \mathrm{E}-04$ & $5.67 \mathrm{E}-02$ & $1.55 \mathrm{E}-02$ \\
3150 & $6.38 \mathrm{E}-04$ & $1.19 \mathrm{E}-03$ & $5.20 \mathrm{E}-04$ \\
\hline
\end{tabular}

From Table 1- Table 3, it can be seen that the bearing shows irregular displacement responses in all directions under different excitation frequencies. In the middle adjusting position, the maximum displacement response value is $6.35 \mathrm{E}-02 \mathrm{~mm}$, which occurs in y direction, and the excitation frequency is $2700 \mathrm{~Hz}$; in the extreme left adjusting position, the maximum displacement response value is $4.96 \mathrm{E}-02 \mathrm{~mm}$, which occurs in y direction, and the excitation frequency is also $2700 \mathrm{~Hz}$; in the extreme right adjusting position, the maximum displacement response value is $5.67 \mathrm{E}-02 \mathrm{~mm}$, which occurs in y direction, and the excitation frequency is still $2700 \mathrm{~Hz}$. Therefore, $2700 \mathrm{~Hz}$ is the dangerous vibration frequency in the adjusting course of the bearing.

In order to reveal further sustained dynamic response characteristics of the bearing, it is necessary to analyze the stress state under the dangerous vibration frequency of $2700 \mathrm{~Hz}$. It is the same as above, three representative positions are selected to analyze, namely, the middle adjusting position, the extreme left adjusting position and the extreme right adjusting position. Fig.3-Fig.5 
show respectively the equivalent stress nephograms of the bearing in three representative positions under the dangerous vibration frequency of $2700 \mathrm{~Hz}$.

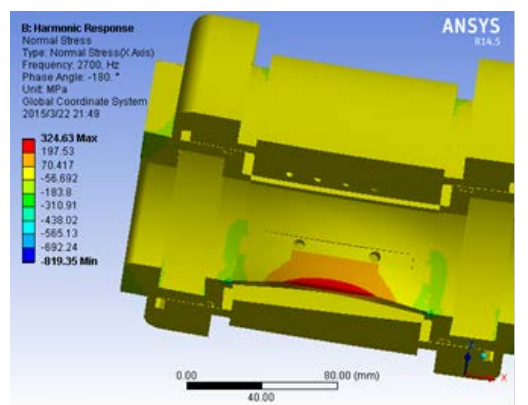

Fig.3 Equivalent stress nephogram in the middle adjusting position

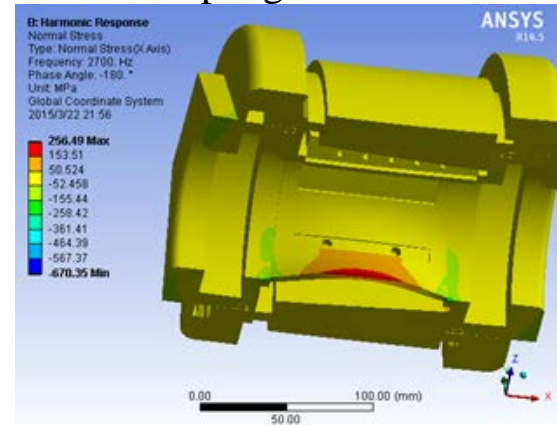

Fig.4 Equivalent stress nephogram in the extreme left adjusting position

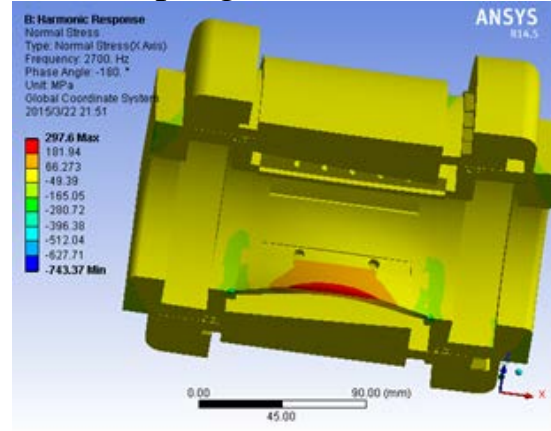

Fig.5 Equivalent stress nephogram in the extreme right adjusting position

It can be seen from Fig.3-Fig.5 that maximum equivalent stress values of the bearing are respectively $324.63 \mathrm{MPa}$, $256.49 \mathrm{MPa}$ and $297.6 \mathrm{MPa}$ in the middle, the extreme left and the extreme right adjusting position when the vibration frequency is $2700 \mathrm{~Hz}$, and the place where maximum stress occurs lies in the middle between the static pressure oil cavity and the oil guide slot. The material of the bearing is tin bronze, whose allowable stress is $175 \mathrm{Mpa}$, so, under the dangerous vibration frequency of $2700 \mathrm{~Hz}$, the maximum stresses of the bearing are all beyond the yield strength of the material. Therefore, in order to maintain good sustained dynamic response characteristics of the bearing, excitation frequency of the bearing can not exceed $2700 \mathrm{~Hz}$. In accordance with the above analysis method, through calculating, the bearing has good harmonic response performances within $1000 \mathrm{~Hz}$ no matter it lies in which adjusting position.

\section{Conclusions}

Hybrid oil film bearing is a core component of high-speed roll grinder, and its good sustained dynamic response characteristics are a key to ensure high precision of the roll grinder. Aiming at a kind of adjustable hybrid oil film bearing in high-speed roll grinder, harmonic response in different adjusting positions is analyzed by means of finite element analysis software, and dangerous vibration frequency of the bearing is found out, and further safe excitation frequency range is confirmed, thus, parameter basis is provided for defining its dynamic properties, and theoretical support is also provided for its engineering application. 


\section{Acknowledgement}

In this paper, the research was sponsored by National Natural Science Foundation of China (Grant No. 51465008, 51165002), and Special Fund of Training Objects on Excellent Young Talents of Science and Technology in Guizhou Province (Grant No. (2013)17).

\section{References}

[1] Zhang Yaoman, Liu Chunshi, Xie Zhikun, et al. Study on the finite element modeling method of spindle assemble of high speed NC machine tool[J]. Manufacturing technology and machine tools, 2008 (9): 76-79.

[2] Du Qiaolian, Zhang Kehua. Numerical analysis of load-bearing capacity of oil film for hydro-hybrid bearing using finite element method [J]. Transactions of the chinese society of agricultural engineering, 2008, 24(6): 137-140.

[3] Zenglin, G, Toshio, H, Gordon, K R. Application of CFD analysis for rotating machinery - Part I: Hydrodynamic, hydrostatic bearings and squeeze film damper [J]. Journal of Engineering for Gas Turbines and Power, 2005, 127(2): 445-451.

[4] Su, J C T, Lie, K N. Rotation effects on hybrid hydrostatic/hydrodynamic journal bearings [J]. Industrial Lubrication and Tribology, 2001, 53(6): 261-269.

[5] Cui Zhong, Wen Guilin, Chen Guiping, et al. Whole machine dynamic characteristic analysis of high speed grinder[J]. China mechanical engineering, 2010, 21 (7): 782-787.

[6] Wu Huaichao, Linghu Kejun, Sun Guanchao, et al. Optimization design of liquid hybrid bearing in grinding head of high-speed roll grinder based on genetic algorithm[J]. China mechanical engineering, 2015, 26 (18): 2496-2500.

[7] Huang Zhixin, Liu Chengzhu. Super study manual of ANSYS Workbench14.0 [M]. Beijing: Posts \& Telecom Press, 2013. 